\title{
Expression pattern of CXC chemokine receptor-4 is correlated with lymph node metastasis in human invasive ductal carcinoma
}

\author{
Masahiro Kato, Joji Kitayama, Shinsuke Kazama and Hirokazu Nagawa
}

Department of Surgical Oncology, The University of Tokyo, Tokyo, Japan

Corresponding author: Joji Kitayama (e-mail: kitayama-1su@h.u-tokyo.ac.jp)

Received: 20 Mar 2003 Revisions requested: 25 Apr 2003 Revisions received: 26 May 2003 Accepted: 30 Jun 2003 Published: 17 Jul 2003

Breast Cancer Res 2003, 5:R144-R150 (DOI 10.1186/bcr627)

(C) 2003 Kato et al., licensee BioMed Central Ltd (Print ISSN 1465-5411; Online ISSN 1465-542X). This is an Open Access article: verbatim copying and redistribution of this article are permitted in all media for any purpose, provided this notice is preserved along with the article's original URL.

\begin{abstract}
Background: The stromal cell-derived factor-1/CXC chemokine receptor-4 (SDF-1/CXCR4) signal has been shown to be important in various immunological reactions. Recent studies have suggested that CXCR4 is expressed in certain cancer cells and that they use this chemokine receptor efficiently for metastasis formation.
\end{abstract}

Method: The expression of CXCR4 was evaluated by immunohistochemical study in 79 surgically resected invasive ductal carcinomas, and the relation between the staining pattern and clinicopathological features was examined.

Results: CXCR4 was diffusely and homogeneously expressed in 59 cancers, which were further divided into 28 highexpression and 31 low-expression cancers by their staining intensity. The other 20 cancers showed heterogeneous immunoreactivity in tumor tissue, which was defined as focal type. In comparison with the diffuse type, focal type tumors showed significantly more extensive lymph node metastasis, because the number and extent of metastatic nodes were larger in the focal than the diffuse type. In the diffuse type, the rate of node-positive cases did not show a difference in staining intensity. However, high-CXCR4 tumors showed more extensive nodal metastasis in comparison with low-expression tumors. In contrast, the expression pattern of CXCR4 did not have a significant correlation with hematogeneous metastasis. The overall survival of these patients tended to be better in the diffuse type than in the focal type, although the difference was not statistically significant.

Conclusion: The expression pattern of CXCR4 was significantly correlated with the degree of lymph node metastasis in breast cancers. Our data suggest that CXCR4 might be particularly important in facilitating metastasis through the lymphatic system.

Keywords: CXCR4, chemokine, breast cancer, immunohistochemistry, SDF-1

\section{Introduction}

The chemokines, a family of $8-10 \mathrm{kDa}$ chemotactic cytokines, possess a wide range of biological activities, including the regulation of leukocyte trafficking, the modulation of hematopoietic cell proliferation and adhesion to extracellular matrix molecules [1]. Stromal cell-derived factor-1 (SDF-1) belongs to the CXC chemokine family and has potent chemotactic activity for lymphocytes [2]. CXC chemokine receptor-4 (CCR4) is the only physiological receptor for SDF-1, and has also been shown to be a co-receptor used by HIV in infecting CD4 lymphocytes $[3,4]$. It is well known that peripheral blood lymphocytes preferentially localize to peripheral lymphoid tissues, such as lymph nodes; this is called the homing phenomenon.
Hematopoietic stem cells also 'home' to bone during fetal life and during marrow transplantation [5]. In this context, the SDF-1/CXCR4 signal has been shown to be a critical molecular determinant for these events $[6,7]$.

Muller and colleagues have examined the expression of chemokines and their receptors in breast cancer tissue, and explored the possibility that metastatic breast cancer cells were responsive to stimulation by chemokines [8]. They showed that CXCR4 is highly expressed in malignant breast cancer but not in normal breast tissue, and the ligand SDF-1 was highly expressed in bone marrow, lung and lymph nodes, where breast cancer cells metastasize preferentially. Moreover, they demonstrated that neutraliza- 
tion with a specific monoclonal antibody against CXCR4 effectively inhibited the metastasis of breast cancer cells to the lung or lymph nodes in mice. Similar studies have shown that metastasis to bone marrow in neuroblastoma [9], prostate cancer [10], and rhabdomyosarcoma [11] is, at least in part, dependent on the SDF-1/CXCR4 pathway. Because cancer cells often share phenotypic characteristics with hematopoetic stem cells, it is supposed that various cancers might use the SDF-1/CXCR4 pathway during their spread to other tissues [12,13].

However, the immunostaining pattern of CXCR4 in various cancer tissues has not been well documented, although the receptor has been shown to be highly expressed in human brain tissue [14,15] and colonic epithelial cells [16]. In this study we therefore examined the expression of CXCR4 protein in surgically resected human ductal carcinomas by immunohistochemical staining, and analyzed whether the expression pattern of this chemokine receptor is correlated with metastatic potential and is predictive of clinical outcome in these patients.

\section{Materials and methods Immunohistochemical staining}

Seventy-nine invasive ductal carcinomas, which were surgically resected in the Department of Surgery, The University of Tokyo, from 1990 to 1996 , were included in this study. In all cases, ipsilateral axillar lymph node dissection was performed. Two serial sections $3 \mu \mathrm{m}$ thick, of tissue fixed in 10\% formalin and embedded in paraffin, were made from a representative block of each cancer. The first section was stained with hematoxylin and eosin, and the second was used for immunostaining for CXCR4. For immunostaining, paraffin-embedded sections were placed on poly-L-lysine-coated glass slides, and air-dried at room temperature. Deparaffinized and rehydrated sections were heated in a microwave oven for 20 minutes in citrate buffer to retrieve antigenic activity, then cooled for 60 minutes at room temperature. Endogenous peroxidase activity was inhibited by incubation with $0.3 \%$ hydrogen peroxide in methanol for 20 minutes at room temperature.

After non-specific reactions had been blocked with $10 \%$ normal rabbit serum, the sections were first incubated with a murine anti-human CXCR4 monoclonal antibody (BD Pharmingen, San Diego, CA) for 1 hour at a dilution of $1: 400$. The sections were then incubated with biotinylated rabbit anti-mouse immunoglobulin for 30 minutes and next with streptavidin-peroxidase complex for 15 minutes. Careful rinses were performed with several changes of phosphate-buffered saline between each stage of the procedure. The color was developed with diaminobenzidine. The sections were lightly counterstained with hematoxylin and mounted. Negative controls were performed by replacing the primary antibody with phosphate-buffered saline.

\section{Evaluation and statistical analysis}

The immunostained specimens were evaluated by two different observers (MK and SK) without knowledge of the clinicopathological features. In cases of diffuse type tumors, if both investigators agreed that the staining intensity of cancer cells was clearly more than that of interstitial infiltrates, the tumor was categorized as high-expression; other tumors were categorized as low-expression. All statistical analyses were performed with the SAS program. The association of staining patterns with clinicopathological features was assessed with the $\chi^{2}$ test and the unpaired Student $t$-test. The survival rates were calculated with the Kaplan-Meier method and $P$ was determined by log-rank test. $P<0.05$ was considered significant in all statistical analyses.

\section{Results}

In all 79 specimens of breast cancers, normal glands were not significantly stained, whereas interstitial infiltrates were weakly stained with the monoclonal antibody against CXCR4. In contrast, in all cases, at least some carcinoma cells clearly showed positive staining in the cytoplasm, nuclei, nucleoli, and membrane, although the staining pattern and intensity differed between tumors (Fig.1). These 79 cases were divided into two groups according to their staining pattern. In 59 (75\%) cases, almost all carcinoma cells were homogeneously stained by anti-CXCR4 monoclonal antibody, and these were categorized as diffuse type. Diffuse type tumors were further classified into two groups according to their staining intensity in the cytoplasm: 28 cases had high expression of CXCR4 and 31 had low expression. The other 20 (25\%) tumors showed heterogeneous staining for CXCR4 and could not be separated by their staining intensity. Positive cells were segregated in focal areas of the cancers or the staining intensity varied between individual carcinoma cells, whereas some carcinoma cells totally lacked expression of CXCR4. These cases were all included in the focal type.

The relation between the staining patterns and clinicopathological factors is shown in Tables 1 and 2. The percentage of large tumors was relatively high in the focal type, although the difference was not statistically significant. There were no differences in pathological type, histological grade, or estrogen receptor expression between focal type and diffuse type tumors (Table 1). In tumors with focal type expression of CXCR4, lymph node metastases were observed in 12 cases (60\%), which tended to be high in comparison with the diffuse type, although the difference was not statistically significant. However, in the 12 node-positive tumors, 9 cases $(75 \%)$ showed involvement of apical axillar lymph nodes (level III) or more distant nodes, and the rate was significantly higher than in the diffuse type (Table 3). Accordingly, the number of metastatic nodes in the focal type was also significantly greater than in the diffuse type (Table 3 ). 


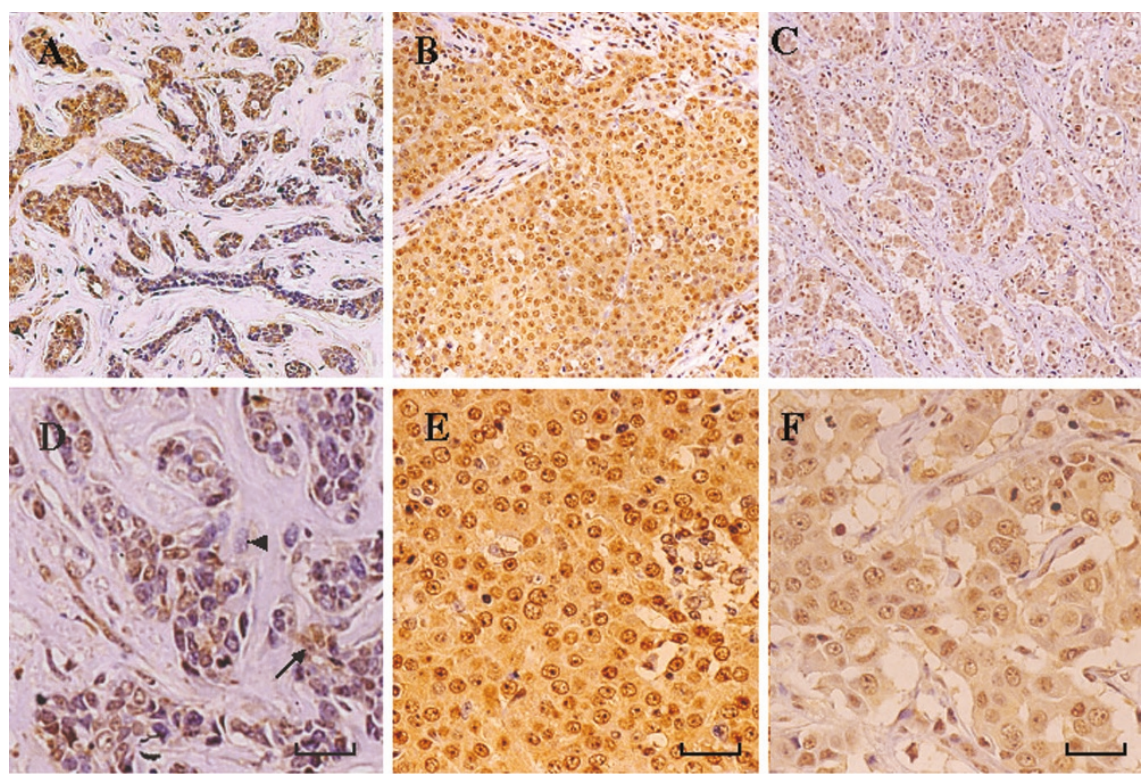

Staining patterns of breast cancers with monoclonal antibody against CXCR4. Tumors consist of carcinoma cells with different immunoreactivities, defined as focal type (A, D). (A) Carcinoma cells located at the upper left area were positively stained, whereas cells in lower right area were negative. (D) Each cell shows a different immunoreactivity for CXCR4; the arrow and arrowhead indicate representative positive and negative carcinoma cells, respectively. In other cases, most carcinoma cells are diffusely and homogeneously stained, but the staining intensity differs between the high (B, E) and low (C, F) expression groups. Original magnifications: $\times 40(A-C) ; \times 200(D-F)$. Scale bars, $20 \mu \mathrm{m}$.

In the diffuse type, lymph node metastasis was observed in 13 of 28 cases with high expression of CXCR4 and in 13 of 31 cases with low expression (Table 2). As shown in Table 3 , in the 13 node-positive tumors with high expression of CXCR4, the metastases were confined within N1 in 5 cases $(38 \%)$, and 8 cases (62\%) were associated with $\mathrm{N} 2$ or more distant lymphatic metastasis, whereas only 1 case $(7.7 \%)$ showed lymphatic metastasis in N2 or a wider area in tumors with low expression of CXCR4. In addition, the number of metastatic nodes was significantly greater in high expression than in low expression of CXCR4. Therefore, among the three groups, focal type tumors were associated with the highest number of metastatic nodes, and the expression level of CXCR4 showed a positive correlation with the number of metastatic nodes in the diffuse type.

In contrast with lymphatic spread, venous invasion and distant metastasis did not show a significant difference between the focal and diffuse types, or between high and low expression levels of CXCR4 in the diffuse type (Tables 1 and 2). However, the cases that showed metastasis in more than two organs tended to be higher in the focal type. Multiple metastasis was observed in 5 cases $(25 \%)$ in the focal type, and in 3 cases (11\%) and 1 case (3.2\%) in the diffuse high-expression and low-expression types, respectively.
The prognosis of patients is shown in Figure 2. In accordance with the rate of multiple metastasis, both the survival and disease-free survival rates tended to be lower in the focal type, although the difference was not statistically significant.

\section{Discussion}

The role of the SDF-1/CXCR4 signal system has been investigated mainly in the field of immunology, such as hematopoiesis, lymphocyte homing, or HIV infection. Muller and colleagues showed clearly that breast cancer cells express CXCR4 highly, and functional blockade of this receptor leads to the inhibition of metastasis to bone marrow and lymph nodes (8). Their results strongly suggested the importance of chemokine signals in breast cancer metastasis, and encouraged us to examine the relationship between the protein expression level of CXCR4 and the clinical features of various breast cancers.

Initially, we proposed that most of the breast cancers would contain carcinoma cells with various degrees of expression of CXCR4 at the protein level and that cancer cells with a high expression of CXCR4 would have high metastatic potential. However, in this study we found that most breast cancer cells expressed the CXCR4 protein diffusely at equal levels, and heterogeneity was rarely observed in immunohistochemical staining. In contrast, 
Table 1

Clinicopathological features and staining patterns of CXCR4 in
breast cancer
breast cancer

\begin{tabular}{|c|c|c|c|}
\hline Feature & $\begin{array}{l}\text { Focal expression } \\
\quad(n=20)\end{array}$ & $\begin{array}{l}\text { Diffuse expression } \\
\qquad(n=59)\end{array}$ & $P$ \\
\hline Age (years) & $47.5 \pm 7.5$ & $53.2 \pm 7.5$ & NS \\
\hline \multicolumn{4}{|l|}{ Sex } \\
\hline Male & 0 & 1 & \\
\hline Female & 19 & 58 & NS \\
\hline \multicolumn{4}{|l|}{ Tumor size $(\mathrm{cm})$} \\
\hline T1 & 6 & 19 & \\
\hline T2 & 10 & 33 & \\
\hline T3 & 4 & 7 & NS \\
\hline \multicolumn{4}{|l|}{ Pathological type } \\
\hline Papillotubular & 5 & 20 & \\
\hline Solid tubular & 1 & 9 & \\
\hline Scirrhous & 13 & 27 & \\
\hline Others & 1 & 3 & NS \\
\hline \multicolumn{4}{|c|}{ Histological grade } \\
\hline 1 & 5 & 27 & \\
\hline 2 & 8 & 23 & \\
\hline 3 & 7 & 9 & NS \\
\hline \multicolumn{4}{|c|}{ Lymphatic invasion } \\
\hline Negative & 9 & 31 & \\
\hline Positive & 11 & 28 & NS \\
\hline \multicolumn{4}{|l|}{ Venous invasion } \\
\hline Negative & 15 & 41 & \\
\hline Positive & 5 & 18 & NS \\
\hline \multicolumn{4}{|c|}{ Estrogen receptor } \\
\hline Negative & 6 & 23 & \\
\hline Positive & 12 & 29 & \\
\hline Unknown & 2 & 7 & NS \\
\hline \multicolumn{4}{|c|}{ Lymph node metastasis } \\
\hline Negative & 8 & 33 & \\
\hline Positive & 12 & 26 & NS \\
\hline \multicolumn{4}{|l|}{ Distant metastasis } \\
\hline Negative & 14 & 46 & \\
\hline Positive & 6 & 13 & NS \\
\hline
\end{tabular}

The differences between the two groups were evaluated by $\chi^{2}$ tests. NS, not significant. T1, $\leq 2.0 \mathrm{~cm} ; \mathrm{T} 2,>2.0, \leq 5.0 \mathrm{~cm} ; \mathrm{T} 3,>5.0 \mathrm{~cm}$.
Table 2

Clinicopathological features and CXCR4 staining intensities of diffuse type breast cancer

\begin{tabular}{|c|c|c|c|}
\hline Feature & $\begin{array}{l}\text { High intensity } \\
\quad(n=28)\end{array}$ & $\begin{array}{l}\text { Low intensity } \\
\qquad(n=31)\end{array}$ & $P$ \\
\hline Age (years) & $52.4 \pm 8.5$ & $54.2 \pm 9.6$ & NS \\
\hline \multicolumn{4}{|l|}{ Sex } \\
\hline Male & 1 & 0 & \\
\hline Female & 27 & 31 & NS \\
\hline \multicolumn{4}{|l|}{ Tumor size (cm) } \\
\hline$\leq 2.0$ & 9 & 10 & \\
\hline $2.0-5.0$ & 15 & 18 & \\
\hline$>5.0$ & 4 & 3 & NS \\
\hline \multicolumn{4}{|l|}{ Pathological type } \\
\hline Papillotubular & 7 & 13 & \\
\hline Solid tubular & 6 & 3 & \\
\hline Scirrhous & 15 & 12 & \\
\hline Others & 0 & 3 & NS \\
\hline \multicolumn{4}{|l|}{ Histological grade } \\
\hline 1 & 12 & 15 & \\
\hline 2 & 11 & 12 & \\
\hline 3 & 5 & 4 & NS \\
\hline \multicolumn{4}{|c|}{ Lymphatic invasion } \\
\hline Negative & 11 & 20 & \\
\hline Positive & 17 & 11 & NS \\
\hline \multicolumn{4}{|l|}{ Venous invasion } \\
\hline Negative & 16 & 25 & \\
\hline Positive & 12 & 6 & NS \\
\hline \multicolumn{4}{|c|}{ Estrogen receptor } \\
\hline Negative & 11 & 12 & \\
\hline Positive & 15 & 14 & \\
\hline Unknown & 2 & 5 & NS \\
\hline \multicolumn{4}{|c|}{ Lymph node metastasis } \\
\hline Negative & 15 & 17 & \\
\hline Positive & 13 & 14 & NS \\
\hline \multicolumn{4}{|l|}{ Distant metastasis } \\
\hline Negative & 21 & 27 & \\
\hline Positive & 7 & 4 & NS \\
\hline
\end{tabular}

The differences between the two groups were evaluated by $\chi^{2}$ tests. NS; not significant.

Table 3

The range and number of metastatic lymph nodes in node-positive breast cancers with different staining patterns for CXCR4

\begin{tabular}{|c|c|c|c|c|c|c|}
\hline \multirow[b]{2}{*}{ Lymph node metastasis } & \multicolumn{2}{|c|}{ Staining pattern } & \multirow[b]{2}{*}{$P$} & \multicolumn{2}{|c|}{ Staining pattern in diffuse type } & \multirow[b]{2}{*}{$P$} \\
\hline & Focal & Diffuse & & High & Low & \\
\hline \multicolumn{7}{|l|}{ Extent of metastasis } \\
\hline $\mathrm{N} 1$ & 3 & 17 & 0.021 & 5 & 12 & 0.025 \\
\hline$\geq \mathrm{N} 2$ & 9 & 9 & & 8 & 1 & \\
\hline Number of metastatic nodes & $12.4 \pm 10.4$ & $5.1 \pm 5.4$ & 0.0071 & $7.8 \pm 6.4$ & $2.5 \pm 1.8$ & 0.0078 \\
\hline
\end{tabular}

The difference between N1 and $\geq \mathrm{N} 2$ was statistically significant between focal and diffuse types, and between high and low expression of CXCR4, by $\chi^{2}$ tests. The numbers of metastatic nodes were also significantly different between focal and diffuse types, and between high and low expression of CXCR4, by Student's $t$-test. N1, metastatic nodes were confined in low and mid axilla area; N2, metastatic nodes were detected at apical axilla area. 
(A)

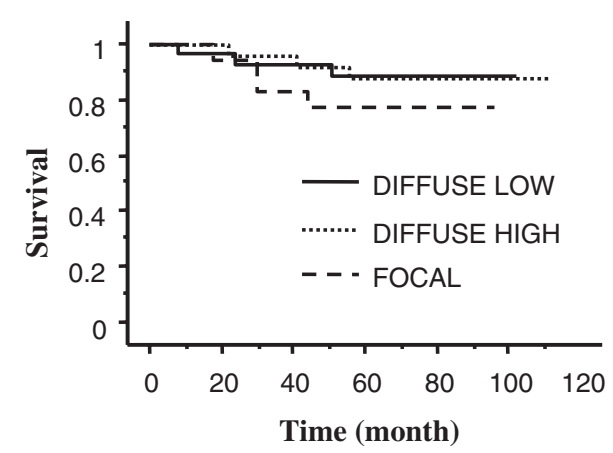

(B)

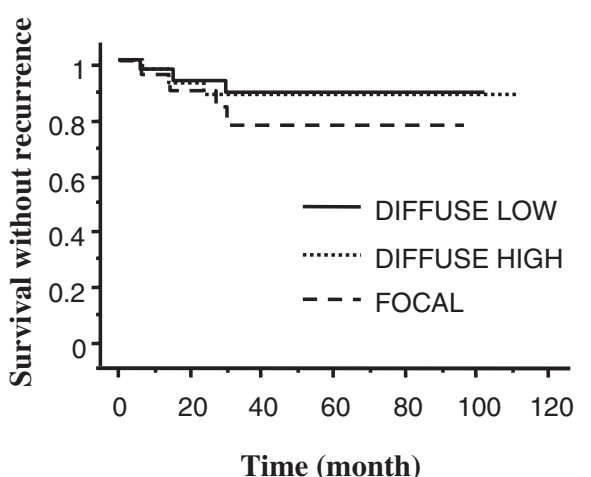

Overall survival (A) and disease-free survival (B) were examined in patients with each CXCR4 expression pattern. $P$ determined by log-rank tests was 0.56 for overall survival and 0.58 for disease-free survival.

20 tumors showed heterogeneous, focal, staining for CXCR4, which was clearly distinguished from other cases with diffuse staining for CXCR4. In most immunoreactive carcinoma cells, the nuclei, nucleoli, nuclear membrane, and cytoplasm are positively stained. The localization of CXCR4 in nuclei has not yet been described. Although the function of this molecule in nuclei needs to be examined, this finding raises a possibility that CXCR4 might have other unknown roles in cancer cells.

Previous studies have shown that CXCR4 is expressed in various cancer cell lines [8,17-21], whereas the immunohistochemical characterization of CXCR4 has been reported only in pancreas cancers in the study by Koshiba and colleagues [22]. They described that CXCR4 was positively stained in the cytoplasm and cell membrane of pancreatic cancer cells, but not in normal pancreatic tissue, and interstitial infiltrates showed weak staining [22]. In their study, the expression level of CXCR4 did not show a significant relation to the clinicopathological features of those pancreatic cancers, although they classified the tumors only by the intensity of immunoreactive cells and did not evaluate the staining patterns. In contrast, our results clearly indicate that tumors with focal staining have a higher potential for lymph node metastasis than diffuse type tumors. Although the exact reason is not clear, one speculation is that the focal expression of CXCR4 might reflect increased heterogeneity in comparison with diffuse type tumors, which might be related to increased malignant potential.

In our results, there was no difference in the rate of nodepositive cases between tumors with high and low expression of CXCR4. However, tumors with high expression of CXCR4 showed more extensive lymphatic spread than those with low expression of CXCR4, because the range in cases of high expression of CXCR4 than in those with low expression. This suggests that the movement of tumor cells from metastatic nodes to secondary lymph nodes might be more dependent on the expression level of CXCR4. SDF-1, the ligand for CXCR4, has been shown to be abundantly expressed in lymph nodes, and is considered to be important for lymphocyte homing $[23,24]$. Therefore, when tumor cells metastasize to sentinel lymph nodes, they are liable to be subjected to considerably higher concentrations of SDF-1 than those staying in the primary site of breast tissue, which might stimulate chemokinesis of tumor cells. In this context, it might be reasonable that tumor cells with high expression of CXCR4 exhibit more extensive lymphatic spread than those with low expression.

Previous experimental studies have suggested that hematogenous metastasis to the lung or bone marrow is partly dependent on CXCR4 in various cancers [8-11]. However, in the present study we could not detect a positive correlation between the expression pattern of CXCR4 and distant metastasis or patient survival. It is not yet clear why CXCR4 expression is related only to lymph node metastasis but not to distant metastasis in this study, because SDF-1 is phylogenetically a primitive chemokine and widely expressed in various organs as well as lymph nodes. Among the sequential steps in the metastatic process, the growth of disseminated cancer cells in metastatic sites is supposed to be the most inefficient step for cancer cells and a key regulator of overall metastatic ability [25]. The regulation of CXCR4 expression in cancer cells in metastatic sites might therefore be important for the development of metastasis formation.

A recent study by Helbig and colleagues has suggested that NF-KB is a potent inducer of cell-surface CXCR4 
expression and thus has a critical role in metastasis in breast cancer cell lines [26]. Because various inflammatory cytokines such as interleukin-1, tumour necrosis factor, and interleukin-8 are potent inducers of NF- $\kappa B$, the presence of these cytokines in secondary sites might be crucial for cell survival through SDF-1-CXCR4 signaling. Because these cytokines are produced mainly by immune cells, regional lymph nodes are supposed to express the cytokines more efficiently and abundantly than other organs against the invasion of cancer cells. Carcinoma cells arrested in lymph node tissues therefore seem to upregulate the CXCR4 molecule easily through the activation of NF- $\kappa B$, which might facilitate the development of clinical metastasis and cause the discrepancy between nodal and distant metastasis. More studies with a larger number of cases are necessary to determine the exact role of the SDF-1/CXCR4 signal in the development of distant metastasis of breast cancer.

In summary, we examined the protein expression of CXCR4 in breast cancers and found that the expression pattern of this chemokine receptor had a significant correlation with the degree of lymph node metastasis, especially with the potential to metastasize from initially involved lymph nodes to secondary nodes. The molecular mechanisms of lymph node metastasis have not been satisfactorily examined, probably because there is insufficient information about the anatomy and physiology of the human lymphatic system. In particular, little is known about the mechanisms that mediate metastasis from already metastatic nodes to adjacent lymph nodes. However, the number of involved nodes has been shown to have a profound influence on postoperative outcome in various cancer patients [27-32]. This suggests that lymph node metastasis, as long as it is localized to a few local lymph nodes, can be safely controlled by surgery alone, whereas once tumor cells have passed the first-line defense lymph nodes they can easily spread to the whole body. From this point of view, analysis of the detailed mechanisms of metastasis from 'sentinel nodes' to 'distant nodes' might have significant clinical importance. CXCR4 is supposed to be one of the important factors facilitating the wide spread of tumor cells through the lymphatic system.

\section{Conclusion}

In breast cancers, the expression pattern of CXCR4 showed a significant correlation with the degree of lymphatic spread but not with hematogenous metastasis. Our results suggest the possibility that CXCR4 is involved in the lymphatic spread of breast cancers. In particular, CXCR4 might be important in facilitating metastasis from 'sentinel' to more distant lymph nodes.

\section{Competing interests}

None declared.

\section{Acknowledgement}

This work was supported by a Grant-in-Aid for Scientific Research from the Ministry of Education, Science, Sports and Culture of Japan and by a Grant from the Ministry of Health and Welfare of Japan.

\section{References}

1. Rollins BJ: Chemokines. Blood 1997, 90:909-928.

2. Bleul CC, Fuhlbrigge RC, Casasnovas JM, Aiuti A, Springer TA: A highly efficacious lymphocyte chemoattractant, stromal cellderived factor 1 (SDF-1). J Exp Med 1996, 184:1101-1109.

3. Nagasawa T, Hirota S, Tachibana K, Takakura N, Nishikawa S, Kitamura Y, Yoshida N, Kikutani H, Kishimoto T: Defects of B-cell lymphopoiesis and bone-marrow myelopoiesis in mice lacking the CXC chemokine PBSF/SDF-1. Nature 1996, 382: 635-638.

4. Bleul CC, Farzan M, Choe H, Parolin C, Clark-Lewis I, Sodroski J, Springer TA: The lymphocyte chemoattractant SDF-1 is a ligand for LESTR/fusin and blocks HIV-1 entry. Nature 1996, 382:829-833.

5. Hardy C: Homing of hematopoietic stem cells to the marrow. Am J Med Sci 1995, 309:260-266.

6. $\mathrm{Kim} \mathrm{CH}$, Broxmeyer HE: SLC/exodus2/6Ckine/TCA4 induces chemotaxis of hematopoietic progenitor cells: differential activity of ligands of CCR7, CXCR3, or CXCR4 in chemotaxis vs. suppression of progenitor proliferation. J Leuk Biol 1999, 66:455-461.

7. Aiuti A, Tavian M, Cipponi A, Ficara F, Zappone E, Hoxie J, Peault $\mathrm{B}$, Bordignon C: Expression of CXCR4, the receptor for stromal cell-derived factor-1 on fetal and adult human lympho-hematopoietic progenitors. Eur J Immunol 1999, 29: 1823-1831.

8. Muller A, Homey B, Soto $H, G e N$, Catron D, Buchanan ME, McClanahan T, Murphy E, Yuan W, Wagner SN, Barrera JL, Mohar A, Verastegui E, Zlotnik A: Involvement of chemokine receptors in breast cancer metastasis. Nature 2001, 410:5056.

9. Geminder H, Sagi-Assif O, Goldberg L, Meshel T, Rechavi G, Witz IP, Ben-Baruch A: A possible role for CXCR4 and its ligand, the CXC chemokine stromal cell-derived factor-1, in the development of bone marrow metastases in neuroblastoma. J Immuno/ 2001, 167:4747-4757.

10. Taichman RS, Cooper C, Keller ET, Pienta KJ, Taichman NS, McCauley LK: Use of the stromal cell-derived factor-1/CXCR4 pathway in prostate cancer metastasis to bone. Cancer Res 2002, 62:1832-1837.

11. Libura J, Drukala J, Majka M, Tomescu O, Navenot JM, Kucia M, Marquez L, Peiper SC, Barr FG, Janowska-Wieczorek A, Ratajczak MZ: CXCR4-SDF-1 signaling is active in rhabdomyosarcoma cells and regulates locomotion, chemotaxis, and adhesion. Blood 2002, 100:2597-2606.

12. Liotta LA: An attractive force in metastasis. Nature 2001, 410: 24-25.

13. Murphy PM: Chemokines and the molecular basis of cancer metastasis. N Engl J Med 2001, 345:833-835.

14. Lavi E, Strizki JM, Ulrich AM, Zhang W, Fu L, Wang Q, O'Connor M, Hoxie JA, Gonzalez-Scarano F: CXCR-4 (Fusin), a co-receptor for the type 1 human immunodeficiency virus (HIV-1), is expressed in the human brain in a variety of cell types, including microglia and neurons. Am J Pathol 1997, 151:1035-1042.

15. Van Der Meer P, Goldberg SH, Fung KM, Sharer LR, GonzalezScarano F, Lavi E: Expression pattern of CXCR3, CXCR4, and CCR3 chemokine receptors in the developing human brain. $J$ Neuropathol Exp Neurol 2001, 60:25-32.

16. Jordan NJ, Kolios G, Abbot SE, Sinai MA, Thompson DA, Petraki $\mathrm{K}$, Westwick J: Expression of functional CXCR4 chemokine receptors on human colonic epithelial cells. J Clin Invest 1999, 104:1061-1069.

17. Zhou $\mathrm{Y}$, Larsen $\mathrm{PH}$, Hao C, Yong VW: CXCR4 is a major chemokine receptor on glioma cells and mediates their survival. J Biol Chem 2002, 277:49481-49487.

18. Hwang JH, Hwang JH, Chung HK, Kim DW, Hwang ES, Suh JM, Kim H, You KH, Kwon OY, Ro HK, Jo DY, Shong M: CXC chemokine receptor 4 expression and function in human anaplastic thyroid cancer cells. J Clin Endocrinol Metab 2003, 88:408-416.

19. Schrader AJ, Lechner O, Templin M, Dittmar KE, Machtens S, Mengel M, Probst-Kepper M, Franzke A, Wollensak T, Gatzlaff P, 
Atzpodien J, Buer J, Lauber J: CXCR4/CXCL12 expression and signalling in kidney cancer. Br J Cancer 2002, 86:1250-1256.

20. Scotton CJ, Wilson JL, Scott K, Stamp G, Wilbanks GD, Fricker $\mathrm{S}$, Bridger G, Balkwill FR: Multiple actions of the chemokine CXCL12 on epithelial tumor cells in human ovarian cancer. Cancer Res 2002, 62:5930-5938.

21. Robledo MM, Bartolome RA, Longo N, Rodriguez-Frade JM, Mellado M, Longo I, van Muijen GN, Sanchez-Mateos P, Teixido J: Expression of functional chemokine receptors CXCR3 and CXCR4 on human melanoma cells. J Biol Chem 2001, 276: 45098-45105

22. Koshiba T, Hosotani R, Miyamoto $Y$, Ida J, Tsuji S, Nakajima S, Kawaguchi M, Kobayashi H, Doi R, Hori T, Fujii N, Imamura M: Expression of stromal cell-derived factor 1 and CXCR4 ligand receptor system in pancreatic cancer: a possible role for tumor progression. Clin Cancer Res 2000, 6:3530-3535.

23. Corcione A, Ottonello L, Tortolina G, Facchetti $P$, Airoldi I, Guglielmino R, Dadati P, Truini M, Sozzani S, Dallegri F, Pistoia V: Stromal cell-derived factor-1 as a chemoattractant for follicular center lymphoma B cells. J Natl Cancer Inst 2000, 92:628635.

24. Arai J, Yasukawa M, Yakushijin Y, Miyazaki T, Fujita S: Stromal cells in lymph nodes attract B-lymphoma cells via production of stromal cell-derived factor-1. Eur J Haematol 2000, 64:323332.

25. Chambers AF, Groom AC, MacDonald IC: Dissemination and growth of cancer cells in metastatic sites. Nat Rev Cancer 2002, 2:563-572.

26. Helbig G, Christopherson KW II, Bhat-Nakshatri P, Kumar S, Kishimoto $\mathrm{H}$, Miller KD, Broxmeyer HE, Nakshatri $\mathrm{H}$ : NF-kB promotes breast cancer cell migration and metastasis by inducing the expression of the chemokine receptor CXCR4. J Biol Chem (in the press).

27. Perrone $F$, Carlomagno $C$, Lauria $R$, De Laurentiis $M$, Morabito $A$, Panico L, Pettinato G, Petrella G, Gallo C, Bianco AR, De Placido S: Selecting high-risk early breast cancer patients: what to add to the number of metastatic nodes? Eur J Cancer 1996, 32A:41-46.

28. Zurrida S, Morabito A, Galimberti V, Luini A, Greco M, Bartoli C Raselli R, Rossi N, Vessecchia G, Cascinelli N, Veronesi U: Importance of the level of axillary involvement in relation to traditional variables in the prognosis of breast cancer. Int $J$ Oncol 1999, 15:475-480.

29. Karpeh MS, Leon L, Klimstra D, Brennan MF: Lymph node staging in gastric cancer: is location more important than number? An analysis of 1,038 patients. Ann Surg 2000, 232: 362-371.

30. Kawahara K, Maekawa T, Okabayashi K, Shiraishi T, Yoshinaga Y, Yoneda S, Hideshima T, Shirakusa T: The number of lymph node metastases influences survival in esophageal cancer. J Surg Oncol 1998, 67:160-163.

31. Roder JD, Schneider PM, Stein HJ, Siewert JR: Number of lymph node metastases is significantly associated with survival in patients with radically resected carcinoma of the ampulla of Vater. Br J Surg 1995, 82:1693-1696.

32. Inoue $\mathrm{T}$, Morita $\mathrm{K}$ : The prognostic significance of number of positive nodes in cervical carcinoma stages IB, IIA, and IIB. Cancer 1990, 65:1923-1927.

\section{Correspondence}

Joji Kitayama MD, Department of Surgical Oncology, The University of Tokyo, 7-3-1 Hongo, Bunkyo-ku, Tokyo 113-0033, Japan. Tel: +8133815 5411 (ext 33246); fax: +81 33811 6822; e-mail: kitayama-1su@h.u-tokyo.ac.jp 